\title{
Cost analysis of adjuvant management strategies in early stage (stage I) testicular seminoma
}

This article was published in the following Dove Press journal:

Research and Reports in Urology

8 January 2015

Number of times this article has been viewed

\section{John A Cox ${ }^{1,2}$ \\ Shefali R Gajjar ${ }^{3}$ \\ Thomas B Lanni Jr ${ }^{4}$ \\ Todd A Swanson'}

'Department of Radiation Oncology, University of Texas Medical Branch, Galveston, TX, ${ }^{2}$ Department of Radiation Oncology, Indiana University School of Medicine, Indianapolis, IN, ${ }^{3}$ University of Texas Medical Branch School of Medicine, Galveston, TX, ${ }^{4}$ Department of Radiation Oncology, William Beaumont Hospital, Royal Oak, MI, USA
Correspondence: Todd A Swanson Department of Radiation Oncology, University of Texas Medical Branch, 30 I University Boulevard, Galveston, 77555 TX, USA

Tel + I 409772253 I

Fax + I 4097470025

Email taswanso@utmb.edu
Background: Acceptable post-orchiectomy adjuvant therapy strategies for stage I seminoma patients include surveillance, para-aortic radiation therapy (RT), dog-leg RT, and a single cycle of carboplatin. The required follow-up recommendations were amended by the National Comprehensive Cancer Network (NCCN) in 2012. Given a cause-specific survival of nearly $100 \%$, a closer analysis of the reimbursement for each treatment strategy is warranted.

Methods: NCCN guidelines were used to design treatment plans for each acceptable adjuvant treatment strategy. Follow-up charges were generated for 10 years based on 2012 (version 1.2012; unchanged in current version 1.2013) and $2011 \mathrm{NCCN}$ (version 2.2011) surveillance recommendations. The 2012 Medicare reimbursement rates were used to calculate each treatment strategy and incremental cost-effectiveness ratios to compare the treatment options.

Results: Under the current NCCN follow-up recommendations, the total reimbursements generated over 10 years of surveillance, para-aortic RT, dog-leg RT, and carboplatin were $\$ 10,643$, $\$ 11,678, \$ 9,662$, and $\$ 10,405$, respectively. This is compared with the reimbursements as per the 2011 NCCN recommendations: \$20,986, \$1 1,517, \$9,394, and \$20,365 respectively. Factoring the rates of relapse into a salvage model, observation was found to be more costly and less effective $(\$-1,831, \$-7,318, \$-7,010)$ in the adjuvant management of stage I seminoma patients.

Conclusion: Based on incremental cost-effectiveness ratios, para-aortic RT, dog-leg RT, and carboplatin are cost-effective options for the treatment of stage I seminoma when compared with observation; however, surveillance could potentially spare as many as $80 \%-85 \%$ of men diagnosed with stage I seminoma from additional therapy after radical inguinal orchiectomy. Such cost and reimbursement analyses are becoming increasingly relevant, but are not meant to usurp sound clinical judgment. Further studies are required to validate these findings.

Keywords: low-stage testicular seminoma, adjuvant management, cost analysis

\section{Introduction}

Testicular seminoma is the most common malignancy in men aged $15-35$ years. ${ }^{1}$ Stage I seminoma patients are initially treated by radical inguinal orchiectomy. Orchiectomy is both diagnostic as well as therapeutic; however, surgical management alone results in relapse rates as high as $20 \%$ at 15 years, ${ }^{2}$ with most relapses identified in the paraaortic lymph nodes. ${ }^{3}$ Nonetheless, disease-specific survival for patients with stage I seminoma approaches $100 \%{ }^{2,4}$ This excellent outcome is related to the effectiveness of salvage therapies, either chemotherapy-based or radiation-based, as pure seminoma tumors display high rates of sensitivity to chemotherapy and radiation therapy (RT).

Concerns about long-term side effects, such as infertility and second malignancies, given this near zero cancer-specific mortality rate, have led to migration away 
from the historical adjuvant standard of care, which has been post-orchiectomy RT, despite reductions of 5-year relapse rates with RT. $^{5-7}$ Reduced field size and total dose have not overcome these concerns..$^{4,8-10}$ Surveillance alone arose as an alternative, given the opportunity to spare $80 \%-85 \%$ of young men the potential treatment-related adverse events seen with adjuvant RT. Acceptable outcomes were noted in single-arm surveillance alone cohort studies and a pooled analysis. .,3,11-13 $^{-13}$ More recently, post-orchiectomy chemotherapy has emerged as an accepted alternative. ${ }^{14,15}$ The Medical Research Council TE 19/EORTC 30982 noninferiority randomized trial comparing single-dose carboplatin with adjuvant RT, with a median follow-up of 6.5 years, confirmed the noninferiority of single-dose carboplatin compared with RT. ${ }^{15}$

Currently, the three acceptable treatment options for patients with stage I seminoma following orchiectomy (National Comprehensive Cancer Network [NCCN] guidelines 1.2013) are surveillance alone, chemotherapy with single-agent carboplatin, or RT to the para-aortic nodes with or without irradiation of the ipsilateral pelvic nodes (dogleg technique). All three recommendations are considered category 1 recommendations by the panel and specifically state intervention is appropriate. However, the NCCN panel suggests that for stage I disease with pT1 and pT2 tumors and that do not involve the spermatic cord, that surveillance is the "preferred" treatment recommendation. Further, the surveillance strategy, including posttreatment follow-up recommendations, was significantly attenuated from previous guidelines.

In 2012, the NCCN significantly altered their follow-up recommendations for surveillance as well as post-adjuvant treatment imaging. Imaging is a significant cost in the followup management of seminoma. Indeed, it is the primary cost in the setting of surveillance as well as posttreatment follow-up. Previous reports have evaluated the cost of adjuvant management strategies in the setting of stage I seminoma. ${ }^{16,17}$ More recently, Kollmannsberger et al have recommended that only a computed tomography (CT) scan of the abdomen is needed while abandoning the pelvic part of the CT. ${ }^{18}$ We postulated that the guideline changes would have significant reverberations in the overall cost analysis of each strategy.

In light of the NCCN changes decreasing the follow-up burden on all post-orchiectomy strategies, we sought to readdress the cost analysis of adjuvant management options in patients with stage I seminoma. Indeed, cost is among the reasons cited by physicians to recommend adjuvant treatment. ${ }^{19}$ We assessed the reimbursement cost associated with each modality given the changing thought processes of oncologic physicians caring for these young patients, as highlighted by the recent NCCN guideline changes. Such changes have significant implications with respect to cost-effectiveness of seemly equivalent management strategies that are likely to become more germane to the evolving health care landscape in the USA and abroad.

\section{Materials and methods Key assumptions for model}

The purpose of this study was to assess the changes in the NCCN guidelines for stage I seminoma and evaluate the costs associated with those recommendations. The NCCN guidelines from 2011 and 2012 were used to design postorchiectomy treatment plans for each of the acceptable adjuvant treatment strategies: surveillance alone, singleagent carboplatin (area under the concentration-time curve =7), para-aortic RT (20 Gy), dog-leg field RT (20 Gy), and salvage chemotherapy (bleomycin, etoposide and cisplatin [BEP], three cycles). BEP salvage chemotherapy for three cycles was assumed as the default salvage regimen for relapse in each adjuvant management strategy. This assumption excludes salvage RT, which would be considered standard of care in the relapsed staging equivalent of stage IIA or IIB for patients who elected for initial active surveillance or carboplatin and failed on a para-aortic or pelvic distribution alone. ${ }^{20-23}$ This assumption simplified the comparison for each management strategy. NCCN guidelines for growth factor support and antiemetic use were incorporated into the treatments. Follow-up charges, including weighted costs for salvage using each modality, were generated for 10 years based on both the 2012 and 2011 NCCN guidelines. According to the published literature, ${ }^{15}$ the anticipated failure rate assumed for surveillance alone, either dog-leg RT or paraaortic RT, or carboplatin was $18 \%, 4 \%$, and 5\% respectively. Three assumptions were made for creation of the relapse and salvage BEP costs for our reimbursement models, ie, no patients relapsed after 5 years, no patients were lost to follow-up, and no patients had early relapse.

\section{NCCN guidelines}

The NCCN, a not-for-profit alliance of 23 of the world's leading cancer centers, is dedicated to improving the quality and effectiveness of care provided to patients with cancer. In 2012, the NCCN changed the follow-up criteria for postorchiectomy patients due to a number of findings as discussed above (these follow-up changes are still current as per the most recent version, 1.2013). These changes were based on data from the Medical Research Council TE/EORTC 30982 
study that was recently published and new information regarding the potential of excess radiation exposure with additional imaging tests. With that information in hand, the NCCN issued new recommendations for follow-up and surveillance for each adjuvant option. These changes are reflected in Tables 1 and 2.

\section{Cost}

The reimbursement and facility cost-effectiveness was evaluated with reimbursement models based on 2012 and 2011 Medicare reimbursement fee schedules for facility and professional charges generated based on International Classification of Diseases 9th Edition codes for carboplatin, RT, and salvage BEP. Although Medicare would not be the primary insurance provider for this patient population, it was the most consistent source that could be used in order to conduct the analysis given that reimbursement information for private insurance carriers varies between each hospital (and state). The treatment regimens for each modality were based on the 2012 NCCN guidelines for treatment and management of stage I seminoma. The recommended follow-up schedules were also based on the NCCN guidelines for 2011 and 2012

Table I National Comprehensive Cancer Network follow-up guidelines by modality

\begin{tabular}{|c|c|c|}
\hline Description & $\frac{\text { Quantity }}{2011}$ & $\frac{\text { Quantity }}{2012}$ \\
\hline \multicolumn{3}{|l|}{ Surveillance } \\
\hline E\&M expanded/low MDM PF & 20 & 14 \\
\hline CT abdomen and pelvis with contrast & 20 & 7 \\
\hline Alpha-fetoprotein & 20 & 14 \\
\hline Lactate dehydrogenase & 20 & 14 \\
\hline Human chorionic gonadotropin & 20 & 14 \\
\hline \multicolumn{3}{|l|}{ Single-agent carboplatin } \\
\hline E\&M expanded/low MDM PF & 20 & 16 \\
\hline CT abdomen and pelvis with contrast & 20 & 3 \\
\hline Alpha-fetoprotein & 20 & 16 \\
\hline Lactate dehydrogenase & 20 & 16 \\
\hline Human chorionic gonadotropin & 20 & 16 \\
\hline \multicolumn{3}{|l|}{ RT (PA nodes only) } \\
\hline E\&M expanded/low MDM PF & 13 & 14 \\
\hline CT abdomen and pelvis with contrast & 3 & 3 \\
\hline Alpha-fetoprotein & 14 & 14 \\
\hline Lactate dehydrogenase & 14 & 14 \\
\hline Human chorionic gonadotropin & 14 & 14 \\
\hline \multicolumn{3}{|l|}{ RT (dog-leg) } \\
\hline E\&M expanded/low MDM PF & 13 & 14 \\
\hline CT abdomen and pelvis with contrast & 0 & 0 \\
\hline Alpha-fetoprotein & 13 & 14 \\
\hline Lactate dehydrogenase & 13 & 14 \\
\hline Human chorionic gonadotropin & 13 & 14 \\
\hline
\end{tabular}

Abbreviations: $C T$, computed tomography; E\&M, evaluation and management; MDM, medical decision making; PA, para-aortic; PF, patient follow-up; RT, radiotherapy.
Table 2 Treatment and follow-up reimbursement comparison between $201 \mathrm{I}$ and 2012

\begin{tabular}{lll}
\hline $\begin{array}{l}\text { Adjuvant } \\
\text { strategy }\end{array}$ & $\begin{array}{l}\text { 20II Medicare } \\
\text { combined charges }\end{array}$ & $\begin{array}{l}\text { 20I2 Medicare } \\
\text { combined charges }\end{array}$ \\
\hline Surveillance & $\$ 18,80 I$ & $\$ 8,458$ \\
Carboplatin & $\$ 19,758$ & $\$ 7,263$ \\
PA-RT & $\$ 11,031$ & $\$ 11,192$ \\
DL-RT & $\$ 8,908$ & $\$ 9,176$ \\
\hline
\end{tabular}

Abbreviations: $\mathrm{DL}$, dog-leg; PA, para-aortic; RT, radiation therapy.

(these represent the current working guidelines to date, with no interval changes since study initiation, version 1.2013).

\section{Incremental cost-effectiveness ratio}

Cost-effectiveness analyses were performed using incremental cost-effectiveness ratios (ICERs), which were calculated based on the ratio of the difference in reimbursement to the criteria being evaluated. By using this ratio, comparisons can be made between treatment modalities for specific diseases to determine a most cost-effective strategy, thus providing an opportunity to contain costs without jeopardizing patient care. For the ICER analysis, 5-year relapse-free survival was used to compare the outcomes of the different treatment modalities for first-line treatment and salvage therapy. The ICER is calculated by taking the cost of modalities (ie, reimbursement) and the parameter (eg, 5-year relapse-free rate) in question and using the following equation: $\mathrm{ICER}=(\mathrm{A}$ reimbursement $-\mathrm{B}$ reimbursement $) /($ A outcome $-\mathrm{B}$ outcome $)=\$$ per percent improvement when comparing modality A with modality B. The value returned provides a dollar amount per percent improvement in the parameter being evaluated. For our purposes, surveillance was the parameter being evaluated with the ICER calculation. A limitation of this analysis is that when a modality costs less and has better outcomes, negative numbers are returned as no incremental benefit to increased cost is being observed.

\section{Results Descriptive reimbursement rates comparing NCCN 201 I versus 2012 follow-up recommendations}

Significant reimbursement cost savings for patients given adjuvant carboplatin or surveillance alone in 2012 were noted compared with patients with 10-year follow-up recommendations as per 2011 NCCN guidelines. The reimbursement costs, when comparing treatments costs and follow-up costs between 2011 and 2012, were essentially unchanged for both para-aortic RT or dog-leg RT. 


\section{Relapse and salvage BEP reimbursement model}

Factoring the costs of salvage BEP for three cycles after relapse, a salvage reimbursement model was created. Using the 2011 and 2012 frequency of follow-up imaging, physical examinations, and laboratory markers (Tables 3 and 4), significant savings are encountered in year-by-year comparison of surveillance alone and adjuvant carboplatin. The reduced follow-up imaging, examinations, and markers required for surveillance and adjuvant carboplatin management as per the 2012 guidelines provided a greater than $50 \%$ reduction in reimbursement costs as per our salvage model. As expected, para-aortic RT and dog-leg RT reimbursement costs differed little in our salvage reimbursement model when comparing 2011 with 2012.

\section{Alternative relapse and salvage BEP reimbursement model}

Looking critically at the model for our calculations above, we assumed that $18 \%$ (managed by surveillance), $5 \%$ (managed by adjuvant chemotherapy), and $4 \%$ (either adjuvant RT strategy) of patients will relapse at 5 years. No patients were assumed to have relapsed after 5 years. Kollmannsberger et $\mathrm{al}^{24}$ reported median relapse times of 14 months, 14.5 months, and 20 months for patients managed with surveillance, RT, or carboplatin, respectively. This discredits our original hypothetical model and led us to worry about a potential large overestimation of the accrued reimbursement figures for follow-up examinations, markers, and CT-based imaging. Therefore, we modeled a separate relapse model where the relapse timeframe would be a weighted model where $80 \%$ of patients who relapse would have their initial relapse at 12 months, $15 \%$ would relapse at 30 months, and 5\% would not relapse until 5 years. This weighted salvage model showed a reimbursement change from the 2011 to 2012 NCCN guidelines for each modality: surveillance alone $(\$ 12,916.06$ to $\$ 8,518.12)$, carboplatin $(\$ 12,413.35$ to $\$ 5,437.60)$, para-aortic RT $(\$ 4,556.06$ to
$\$ 4,815.63)$, and dog-leg RT $(\$ 2,583.49$ to $\$ 2,843.04)$. The comparison of these two groups (2011 versus 2012), treated as a normal distribution, was found not to be statistically significant $(P=0.228)$, using Student's $t$-test analysis. This crude weighted model shows that even when considering early relapse, the greatest cost is associated with salvage BEP.

\section{ICER with and without factoring salvage}

ICER analysis comparing the reimbursement costs without factoring in a salvage or relapse model, using surveillance as the evaluated parameter and 5-year relapse-free survival rate as the outcome, found surveillance to be less costly than either adjuvant RT option. No incremental benefit was seen for surveillance in the salvage-free model compared with carboplatin given the higher cost associated with surveillance in this model (Table 5). In contrast, when ICER analysis was performed factoring in the results of our salvage BEP reimbursement model, surveillance alone was found to have no incremental benefit, to have a higher cost, and to be less effective when compared with the other strategies.

\section{Discussion}

When evaluating adjuvant strategies for post-orchiectomy stage I seminoma patients, the desire to spare as many as $80 \%-85 \%$ of men further therapy has rapidly been accepted as a preferred therapy given a cancer-specific survival approaching $100 \%$. Additionally, validation studies have not been able to confirm rete testes and testes with a size greater than $4 \mathrm{~cm}$ as risk factors predicting relapse and necessitating the need for adjuvant RT or chemotherapy as opposed to surveillance..$^{25,26}$ Toxicities and risks of second malignancy should be noted for each acceptable treatment option, and clinicians should understand the high likelihood of salvage for such sensitive tumors. ${ }^{19}$ The desire to highlight these concerns and gain a better understanding of the financial impact of therapies led the interest in our hypothetical adjuvant model study. Our current model does not include treatmentrelated morbidity or patient compliance in the cost analysis. Nor are quality of life data available to guide a model for a

Table 3 Weighted reimbursement model (20II) for each modality factoring in salvage BEP

\begin{tabular}{lllll}
\hline $20 I I$ & $\begin{array}{l}\text { Total before factoring } \\
\text { salvage including FU }\end{array}$ & $\begin{array}{l}\text { Relapse } \\
\%\end{array}$ & $\begin{array}{l}\text { BEP } \\
\text { costs }\end{array}$ & $\begin{array}{l}\text { Total with } \\
\text { salvage }\end{array}$ \\
\hline $\begin{array}{l}\text { Observation } \\
\text { Adjuvant RT }\end{array}$ & $\$ 18,80 I$ & 0.18 & $\$ 12,139.00$ & $\$ 20,986.02$ \\
$\quad$ PA RT & $\$ 11,031.00$ & 0.04 & $\$ 12,139.00$ & $\$ 11,516.56$ \\
$\quad$ Dog-leg RT & $\$ 8,908.00$ & 0.04 & $\$ 12,139.00$ & $\$ 9,393.56$ \\
Single-cycle carboplatin & $\$ 19,758.00$ & 0.05 & $\$ 12,139.00$ & $\$ 20,364.95$ \\
\hline
\end{tabular}

Abbreviations: FU, follow-up; BEP, bleomycin, etoposide, cisplatin; PA, para-aortic; RT, radiation therapy. 
Table 4 Weighted reimbursement model (2012) for each modality factoring in salvage BEP

\begin{tabular}{|c|c|c|c|c|}
\hline $\begin{array}{l}2012 \\
\text { Reimbursement }\end{array}$ & $\begin{array}{l}\text { Total before factoring } \\
\text { salvage including FU }\end{array}$ & $\begin{array}{l}\text { Relapse } \\
\%\end{array}$ & $\begin{array}{l}\text { BEP } \\
\text { costs }\end{array}$ & $\begin{array}{l}\text { Total with } \\
\text { salvage }\end{array}$ \\
\hline Observation & $\$ 8,458.00$ & 0.18 & $\$ 12,139.00$ & $\$ 10,643.02$ \\
\hline \multicolumn{5}{|l|}{ Adjuvant RT } \\
\hline PA RT & $\$ 11,192.00$ & 0.04 & $\$ 12,139.00$ & $\$ 11,677.56$ \\
\hline Dog-leg RT & $\$ 9,176.00$ & 0.04 & $\$ 12,139.00$ & $\$ 9,661.56$ \\
\hline Single-cycle carboplatin & $\$ 7,263$ & 0.05 & $\$ 12,139.00$ & $\$ 7,869.95$ \\
\hline
\end{tabular}

Abbreviations: FU, follow-up; BEP, bleomycin, etoposide, cisplatin; PA, para-aortic; RT, radiation therapy.

quality-adjusted life year (QALY) analysis, although it would be expected that all initial therapies would be tolerated well in the acute posttreatment setting.

The descriptive results and hypothetical salvage models in this study show that financial savings are expected in light of the reduced 2012 follow-up guidelines. The cost associated with salvage BEP was the major factor in our weighted relapse/salvage models. The small differences in cost, especially in light of the young age of these patients and expected multiple-decade survival, need to be considered critically. The desire to spare $80 \%-85 \%$ of post-orchiectomy men further therapy is strong and well founded, especially in light of the well described risks of second malignancy and toxicities after adjuvant RT..$^{10,27-32}$ Compared with the results of the survey of practicing radiation oncologists by Arvold et al, ${ }^{19}$ the concern regarding the long-term effects of salvage chemotherapy may be underestimated in the minds of practicing physicians. Kollmannsberger et al, ${ }^{24}$ in their retrospective cohort of 649 patients diagnosed with seminoma (545 patients with stage I, 87 patients with stage II, and 17 patients at stage III disease at diagnosis) reported three patient deaths related to chemotherapy (the majority were stage II and III patients who were treated either with BEP or etoposide and cisplatin). No bleomycin-related hospitalizations or deaths were reported in their cohort. In addition to a non-zero potential salvage chemotherapy mortality rate, van den Belt-Dusebout et $\mathrm{al}^{33}$ raised awareness of an increased

Table 5 ICER analysis comparing surveillance (with or without factoring in reimbursement for BEP salvage) with alternative adjuvant management strategies

\begin{tabular}{lll}
\hline & $\begin{array}{l}\text { ICER analysis } \\
\text { not factoring } \\
\text { BEP salvage } \\
\text { therapy }\end{array}$ & $\begin{array}{l}\text { ICER analysis } \\
\text { factoring } \\
\text { BEP salvage } \\
\text { therapy }\end{array}$ \\
\hline Surveillance versus carboplatin & $\$ 10,307.69$ & $\$-1,831.00$ \\
Surveillance versus PA-RT & $\$ 19,528.57$ & $\$-7,318.00$ \\
Surveillance versus DL-RT & $\$ 5,128.57$ & $\$-7,010.00$ \\
\hline
\end{tabular}

Abbreviations: ICER, incremental cost-effectiveness ratio; BEP, bleomycin, etoposide, cisplatin; \$-, no incremental benefit for surveillance when compared with alternative management strategy; PA, para-aortic; DL, dog-leg; RT, radiation therapy. second malignancy risk with salvage chemotherapy. They reported a nationwide population-based cohort of testicular cancer survivors $(n=2,707)$ treated from 1965 to 1995 in the Netherlands evaluating treatment-specific risks of second malignancies and cardiovascular disease. Seminoma histology represented 1,351 patients in this cohort, and median follow-up for the entire cohort was 17.6 years. The second malignancy risk with para-aortic RT noted a 2.6-fold increase as compared with surgery alone. The second malignancy risk associated with chemotherapy (most commonly BEP for disseminated seminoma and nonseminoma) was increased by 2.1 -fold as compared with surgery alone. Major late complications as related to cardiovascular disease were increased 1.8 -fold by RT and 1.9-fold by chemotherapy as compared with surgery alone.

Likewise, the late effects of CT imaging follow-up are unknown, but have been the source of recent inquiries and publications. CT-based imaging in a population of young men is associated with a non-zero risk of subsequent cancers during patients' lifetimes as described by Tarin et al. ${ }^{34}$ Per this group, the modeled lifetime cancer risk associated with lowdose CT exposure was reported to be $1.9 \%$ for an 18 -year-old given 5 years of $\mathrm{CT}$ scans per NCCN follow-up guidelines. The risk was decreased to $1.2 \%$ for a 40 -year-old seminoma patient per their model calculations. In contrast with the above estimates, Pandharipande et $\mathrm{a}^{35}$ looked at the lifetime expectancy loss attributable to radiation-induced cancers compared with testicular cancer. Modeled radiation-induced cancer incidence and mortality risk, in keeping with data from BEIR VII, ${ }^{36}$ from CT surveillance imaging demonstrated a life expectancy loss attributable to radiation-induced cancers of 24 days, compared with a life expectancy loss attributable to stage I testicular cancer for their 33-year-old "base patient" of 83 days. The authors concluded that lifetime radiation risk estimates, without correcting for the delayed timing of radiation-induced cancer risks, can potentially overshadow the greater short-term health risk.

It is important to note that a simplified model as presented here should not be considered evidence for clinical 
decision-making. It is easily argued that our analysis did not allow for salvage RT in patients who had initial surveillance or carboplatin and would not necessarily have received BEP chemotherapy. Likewise, our model did not account for treatment-related morbidity, second malignancies, or pathway-specific quality of life measurements. We also contend that picking the appropriate variable for an ICER analysis in a model such as ours is difficult. For the purposes of our study, the ICER analysis was performed to test one parameter, ie, surveillance, against the other adjuvant strategies with an outcome of relapse-free survival. Using surveillance as the parameter seems destined to sway the ICER results, given the historically higher relapse rate known in patients under surveillance alone. The appropriate variable, which we argue is unknown, would need to take into account the near $100 \%$ cancer-specific survival for these patients, the rate and morbidity of acute and chronic toxicities, rate of second malignancy (attributable to CT scans, potential salvage RT, and BEP salvage chemotherapy) and quality of life-specific factors that are so important in a population expected to live decades after their initial cancer therapy. There is likely very little need for a randomized trial of surveillance versus carboplatin versus para-aortic RT given what we know today (near 100\% cancer-specific survival), other than for a prospective collection of morbidity data and an instrument to collect quality of life measurements that could make analysis such as ours more valuable. We are not encouraging such an effort, but rather are using our study to highlight the difficulty in predicting the ideal patient outcome, for a population expected to live for decades, for ICER analysis. Availability of more quality-adjusted data in the seminoma literature to undertake a \$/QALY analysis would be of benefit if available from the major Medical Research Council trials or surveillance cohort studies.

Highly curable cancers, such as stage I seminoma, are excellent cases to study for high-quality outcome tracking health care while controlling for cost efficiency. Further follow-up and QALY data are needed going forward to avoid creating hypothetical cohorts and provide our clinicians with more valuable decision-making data. Using our model and ICER analysis, para-aortic RT, dog-leg RT, and single-cycle carboplatin are cost-effective options for the treatment of stage I seminoma patients compared with surveillance alone when factoring salvage BEP reimbursement after potential relapse. The actual amount of savings identified was smaller than expected by our group, and we encourage more robust studies to validate these findings. Given the changing health care landscape, we are expected to ask these cost and reimbursement questions. However, given the small differences seen in our study, we might argue that such reimbursement analyses are not intended to usurp sound clinical judgment or provide strong evidence to avoid a surveillance regimen that could potentially spare $80 \%-85 \%$ of patients from additional therapy for such a curable malignancy even in the salvage setting; rather, they are intended to provide descriptive data and education for health care providers with such curable patients and to again remind them of the morbidities and potential secondary malignancies that can be encountered with adjuvant therapies such as RT and chemotherapy.

\section{Disclosure}

This paper was given as an oral presentation at the 2013 American Society of Clinical Oncology Genitourinary Symposium and updated in poster format for the 2013 American Society for Radiation Oncology annual meeting. The authors have no other conflicts of interest in this work.

\section{References}

1. Swerdlow AJ. Epidemiology of testicular cancer. In: Raghaven D, Scher H, Leibel S, Lange P, editors. Principles and Practice of Genitourinary Oncology. 1st ed. Philadelphia, PA, USA: Lippincott Williams \& Wilkins; 1997.

2. Choo R, Thomas G, Woo T, et al. Long-term outcome of postorchiectomy surveillance for stage I testicular seminoma. Int J Radiat Oncol Biol Phys. 2005;61:736-740.

3. Warde P, Specht L, Horwich A, et al. Prognostic factors for relapse in stage I seminoma managed by surveillance: a pooled analysis. J Clin Oncol. 2002;20:4448-4452.

4. Fossa SD, Horwich A, Russell JM, et al. Optimal planning target volume for stage I testicular seminoma: a Medical Research Council randomized trial. Medical Research Council Testicular Tumor Working Group. J Clin Oncol. 1999;17:1146.

5. Mirimanoff RO. Radiotherapy of testicular seminoma: changes over the past 10 years. Cancer Radiother. 2003;7 Suppl 1:70s-77s.

6. Scholz M, Holtl W. Stage I testicular cancer. Curr Opin Urol. 2003;13: 473-476.

7. Warde P, Jewett MA. Surveillance for stage I testicular seminoma. Is it a good option? Urol Clin North Am. 1998;25:425-433.

8. Jones WG, Fossa SD, Mead GM, et al. Randomized trial of 30 versus $20 \mathrm{~Gy}$ in the adjuvant treatment of stage I testicular seminoma: a report on Medical Research Council Trial TE18, European Organisation for Research and Treatment of Cancer Trial 30942 (ISRCTN18525328). J Clin Oncol. 2005;23:1200-1208.

9. Zagars GK, Ballo MT, Lee AK, et al. Mortality after cure of testicular seminoma. J Clin Oncol. 2004;22:640-647.

10. Travis LB, Curtis RE, Storm H, et al. Risk of second malignant neoplasms among long-term survivors of testicular cancer. $J$ Natl Cancer Inst. 1997;89:1429-1439.

11. Horwich A, Alsanjari N, A'Hern R, et al. Surveillance following orchidectomy for stage I testicular seminoma. Br J Cancer. 1992;65: 775-778.

12. von der Maase H, Specht L, Jacobsen GK, et al. Surveillance following orchidectomy for stage I seminoma of the testis. Eur J Cancer. 1993; 29A:1931-1934.

13. Warde P, Gospodarowicz MK, Banerjee D, et al. Prognostic factors for relapse in stage I testicular seminoma treated with surveillance. J Urol. 1997;157:1705-1710. 
14. Oliver RT, Edmonds PM, Ong JY, et al. Pilot studies of 2 and 1 course carboplatin as adjuvant for stage I seminoma: should it be tested in a randomized trial against radiotherapy? Int J Radiat Oncol Biol Phys. 1994;29:3-8.

15. Oliver RT, Mead GM, Rustin GJ, et al. Randomized trial of carboplatin versus radiotherapy for stage I seminoma: mature results on relapse and contralateral testis cancer rates in MRC TE19/EORTC 30982 study. J Clin Oncol. 2011;29:957-962.

16. Patrice SJ, Patrice JR, Steinberg JS, et al. A cost-effectiveness analysis of surveillance, radiotherapy, and carboplatin in the management of stage I testicular seminoma. J Clin Oncol. 2006;24(18S):6108.

17. Sharda NN, Kinsella TJ, Ritter MA. Adjuvant radiation versus observation: a cost analysis of alternate management schemes in early-stage testicular seminoma. J Clin Oncol. 1996;14:2933-2939.

18. Kollmannsberger C, Tandstad T, Bedard P, et al. Patterns of relapse in patients with clinical stage I testicular cancer managed with active surveillance. J Clin Oncol. August 18, 2014. [Epub ahead of print.]

19. Arvold ND, Catalano PJ, Sweemeu CJ, et al. Barriers to the implementation of surveillance for stage I testicular seminoma. Int J Radiat Oncol Biol Phys. 2012;84:3883-3889.

20. Classen J, Schmidberger H, Meisner C, et al. Radiotherapy for stages IIA/B testicular seminoma: final report of a prospective multicenter clinical trial. J Clin Oncol. 2003;21:1101-1106.

21. Chung PW, Gospodarowicz MK, Panzarella T, et al. Stage II testicular seminoma: patterns of recurrence and outcome of treatment. Eur Urol. 2004; 45:754-759.

22. Garcia-del-Muro X, Maroto P, Guma J, et al. Chemotherapy as an alternative to radiotherapy in the treatment of stage IIA and IIB testicular seminoma: a Spanish Germ Cell Cancer Group Study. J Clin Oncol. 2008;26:5416-5421.

23. Krege S, Boergermann C, Baschek R, et al. Single agent carboplatin for CS IIA/B testicular seminoma. A phase II study of the German Testicular Cancer Study Group (GTCSG). Ann Oncol. 2006;17:276-280.

24. Kollmannsberger C, Tyldesley S, Moore C, et al. Evolution in management of testicular seminoma: Population-based outcomes with selective utilization of active therapies. Ann Oncol. 2011;22:808-814.

25. Chung PW, Daugaard G, Tyldesley, et al. Prognostic factors for relapse in stage I seminoma with surveillance: a validation study. J Clin Oncol. 2010;28:Abstr 4535
26. Chung P, Warde P. Stage I seminoma: adjuvant treatment is effective but is it necessary? J Natl Cancer Inst. 2011;103:194-196.

27. Bachaud JM, Berthier F, Soulie M, et al. Second non-germ cell malignancies in patients treated for stage I-II testicular seminoma. Radiother Oncol. 1999;50:191-197.

28. Chao CK, Lai PP, Michalski JM, et al. Second malignancy among seminoma patients treated with adjuvant radiation therapy. Int J Radiat Oncol Biol Phys. 1995;33:831-835.

29. Glanzmann C, Schultz G, Lutolf UM. Long-term morbidity of adjuvant infradiaphragmatic irradiation in patients with testicular cancer and implications for the treatment of stage I seminoma. Radiother Oncol. 1991;22:12-18.

30. Ruther U, Dieckmann KP, Bussar-Maatz R, et al. Second malignancies following pure seminoma. Oncology. 2000;58:75-82.

31. van Leeuwen FE, Stiggelbout AM, van den Belt-Dusebout AW, et al. Second cancer risk following testicular cancers: a follow-up study of 1,909 patients. J Clin Oncol. 2003;21:1513-1523.

32. Jonker-Pool G, van Basten JP, Hoekstra HJ, et al. Sexual functioning after treatment for testicular cancer: comparison of treatment modalities. Cancer. 1997;80:454-464.

33. van den Belt-Dusebout AW, de Wit R, Gietema JA, et al. Treatment-specific risks of second malignancies and cardiovascular disease in 5-year survivors of testicular cancer. J Clin Oncol. 2007;25: 4370-4378.

34. Tarin TV, Sonn G, Shinghal R. Estimating the risk of cancer associated with imaging related radiation during surveillance for stage I testicular cancer using computerized tomography. J Urol. 2009;181:627-632.

35. Pandharipande PV, Eisenberg JD, Lee RJ, et al. Patients with testicular cancer undergoing CT surveillance demonstrate a pitfall of radiationinduced cancer risk estimates: the timing paradox. Radiology. 2013;266:896-904.

36. National Research Council. Advisory Committee on the Biological Effects of Ionizing Radiation. Health risks from exposure to low levels of ionizing radiation. BEIR VII Phase 2. Washington, DC, USA: National Academy of Sciences; 2006. Available from: http://www.nap edu/openbook.php?isbn=030909156X. Accessed November 4, 2014.
Research and Reports in Urology

\section{Publish your work in this journal}

Research and Reports in Urology is an international, peer-reviewed, open access journal publishing original research, reports, editorials, reviews and commentaries on all aspects of adult and pediatric urology in the clinic and laboratory including the following topics: Pathology, pathophysiology of urological disease; Investigation and treatment of

\section{Dovepress}

urological disease; Pharmacology of drugs used for the treatment of urological disease. The manuscript management system is completely online and includes a very quick and fair peer-review system, which is all easy to use. Visit http://www.dovepress.com/testimonials.php to read real quotes from published authors. 